Fig. 1. The impact of a public emergency health alert on the daily incidence of COVID-19 infection in Hangzhou. The fitted trajectory shows the probable daily incidence with $95 \%$ confidence interval derived from existing data using a log-incidence over time regression model. The split point is the optimal date to split the epicurve into two phases, which best fits the model. Other interventions include restricted movement outside the home, noncontact delivery, online work and teaching, etc.

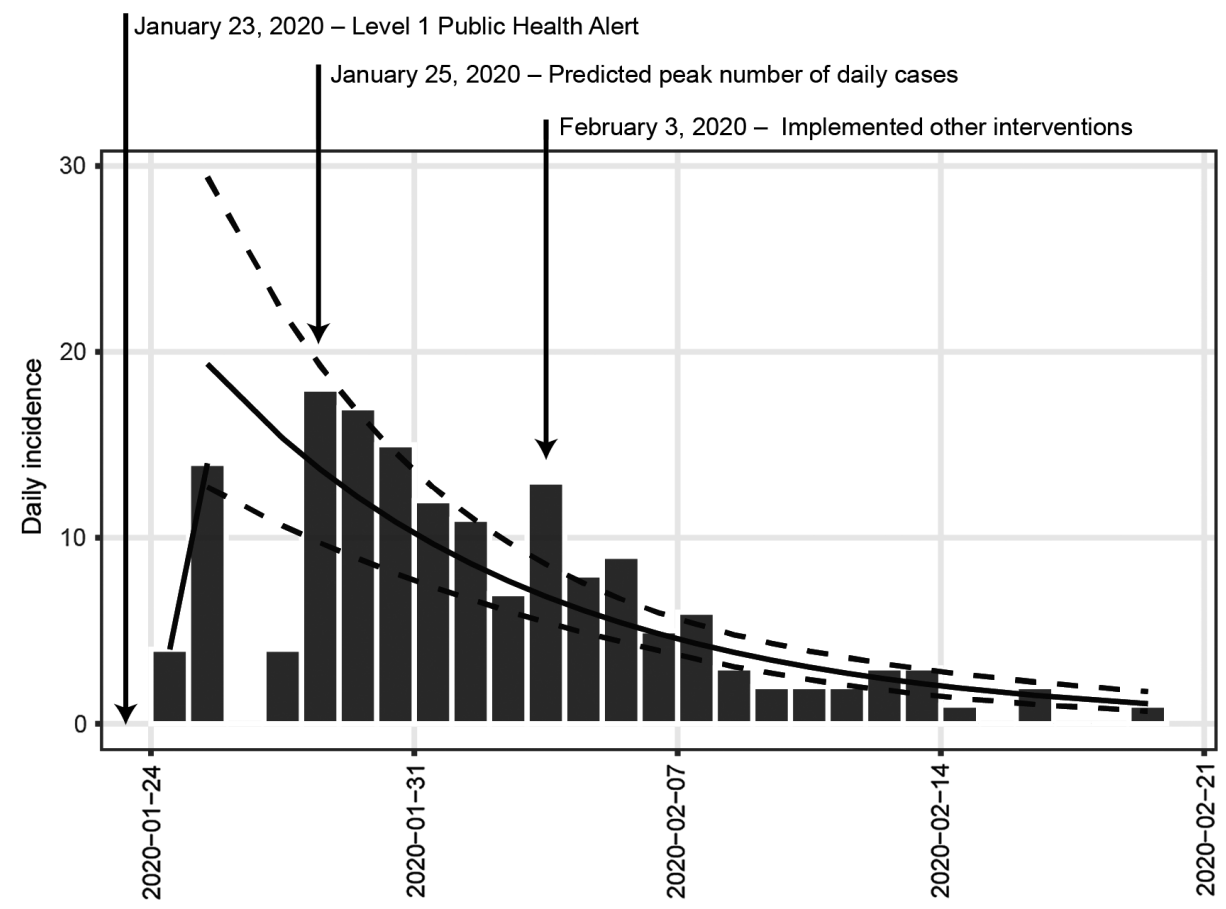

to meet the need to resume production and curb the transmission of the virus as far as possible, Hangzhou arranged chartered transportation to help numbers of migrants return to their work places. Lastly, in cooperation with Alipay, Hangzhou adopted the health quick-response (QR) code system on February 11, 2020, which were designated by green, yellow, or red. People who wanted to get into Hangzhou needed to submit their travel history and health information online in advance. Residents with a green code indicated they had a low current risk of being infected, while residents with yellow or red codes were quarantined for 7 or 14 days and were required to report their health condition daily to exclude infection before the code was changed to green. This health surveillance system has now been applied in most cities in Zhejiang province and will be promoted in other provinces.

Although the effect of prevention and control measures is evident, Hangzhou continues to face huge challenges owing to its large immigrant population. However, this city has already learned much from this epidemic, and we hope that some of our experiences will assist others in their regions.

Acknowledgments. None.

Financial support. No financial support was provided relevant to this article.

Conflicts of interest. All authors report no conflicts of interest relevant to this article.

\section{References}

1. Huang C, Wang Y, Li X, et al. Clinical features of patients infected with 2019 novel coronavirus in Wuhan, China. Lancet 2020;395:497-506.

2. Epidemic situation of new coronavirus pneumonia in Zhejiang province, 2020. Health Commission of Zhejiang Province website. http://www.zjwjw. gov.cn/art/2020/2/21/art_1202194_41958075.html. Published 2020. Accessed February 21, 2020.

3. Kamvar Z N, Cai J, Pulliam J, Schumacher J, Jombart T. Epidemic curves made easy using the R package incidence. F1000Res 2019;8:139.

\title{
COVID-19 positive test result from a private hospital laboratory: Neglecting to report and problems with national infection control
}

\author{
Won Sriwijiatalai ${ }^{1}$ and Viroj Wiwanitkit ${ }^{2,3}$ \\ ${ }^{1}$ TWS Medical Center, Bangkok, Thailand, ${ }^{2}$ Dr DY Patil University, Pune, India and ${ }^{3}$ Hainan Medical University, Haikou, China
}

Author for correspondence: Won Sriwijiatalai, E-mail: wonsriwi@gmail.com

Cite this article: Sriwijiatalai W and Wiwanitkit V. (2020). COVID-19 positive test result from a private hospital laboratory: Neglecting to report and problems with national infection control. Infection Control \& Hospital Epidemiology, 41: 875-876, https://doi.org/10.1017/ice.2020.93
To the Editor-The new coronavirus disease (COVID-19) is a new global public health problem. It already affects more than 140 countries around the world. Thailand is the second country in the timeline of disease pandemic. ${ }^{1}$ The infection has occurred 
since early January 2020, and COVID-19 remains uncontrollable problem. The Thai Ministry of Public Health tried several methods to counteract the disease outbreak. As a legal control, COVID-19 is included on the national list of infectious diseases under surveillance. The law requires that when a medical center detects this disease, an official reports it to the governmental center for disease control (CDC) within 3 hours. Violation of this legal control should result in a punitive consequence.

The exact advantage of this legal regulation regarding COVID-19 control is an interesting issue. In Thailand, not only governmental hospitals but also some private hospitals have the ability to conduct laboratory diagnosis of COVID-19. Among 82 cases of COVID-19 in Thailand overall (as of March 15, 2020), in 1 interesting case the patient self-declared infection via Instagram but no official report had been filed with the local CDC. This patient had received a positive laboratory result from a private hospital. This case was finally confirmed as a case of COVID-19, but it appears that the private hospital may have neglected to report it, violating the legal requirement for disease reporting. This example represents a big challenge faced by hospitals in infection control. Good data collection is important to obtaining high-quality surveillance data, which is imperative for infectious disease control. ${ }^{2}$ At times, poor, unethical, private hospitals do not follow the disease control guidelines. In a disease outbreak, collaboration from hospitals is required, and strict legal regulation of the disease control system should be undertaken. In cases of violation, the poor role model should be punished.

\section{Acknowledgments.}

Financial support. No financial support was provided relevant to this article.

Conflicts of interest. All authors report no conflicts of interest relevant to this article.

\section{References}

1. Yasri S, Wiwanitkit V. Editorial: Wuhan coronavirus outbreak and imported case. Adv Trop Med Pub Health Int 2019;9:1-2.

2. Kostkova P. Disease surveillance data sharing for public health: the next ethical frontiers. Life Sci Soc Policy 2018;14:16.

\title{
Harmonizing the COVID-19 cacophony: People need guidance
}

\author{
Taha Bin Arif MBBS (1) and Aiman Ali MBBS
}

MBBS, Dow Medical College, Dow University of Health Sciences, Karachi, Pakistan

To the Editor-The COVID-19 pandemic caused by a novel coronavirus (SARS-CoV-2) has sounded danger alarms across the globe. According to a report by the World Health Organization (WHO), >292,142 confirmed cases had been identified worldwide as of March 21, 2020. ${ }^{1}$ Although some differences in the real-world mortality rate and the mortality rate were reported in a few published clinical series, a total of 1,772 deaths with an average mortality rate of $2.5 \%$ was reported by the Chinese Center for Disease Control and Prevention on February 16, 2020. ${ }^{2}$ With the rise in global anxiety, the WHO declared COVID-19 the sixth international public health emergency on January 30, 2020. This pandemic could have devastating outcomes across the world if the viral spread is not controlled by public health efforts.

The origin of coronavirus, a single-stranded enveloped RNA virus, dates back in 1960s. The first coronaviruses discovered caused infectious bronchitis in chickens. Two other viruses obtained from nasal secretions of human patients with common colds were named human coronavirus 229E and human coronavirus OC43. Subsequently, other members of this family have been identified, including SARS-CoV in 2003, HCoV NL63 in 2004, HKU1 in 2005, MERS-CoV in 2012, and SARS-CoV-2 (formerly named 2019-nCoV) in 2019. ${ }^{3}$ Most of these virus species cause severe respiratory infections in humans.

Overall, the clinical features of COVID-19, caused by SARSCoV-2, correspond to common influenza. The clinical

\footnotetext{
Author for correspondence: Taha Bin Arif, E-mail: tahaarif20@yahoo.com Cite this article: Arif TB and Ali A. (2020). Harmonizing the COVID-19 cacophony: People need guidance. Infection Control \& Hospital Epidemiology, 41: 876-877, https:// doi.org/10.1017/ice.2020.105
}

manifestations of COVID-19 pneumonia, as demonstrated by some studies, have varied among cases. Fever is the predominant symptom followed by cough, dyspnea, myalgia, headache, and diarrhea. ${ }^{1}$ An effective cure of COVID-19 by antiviral therapy and vaccination is currently being developed. However, considering previous management plans for MERS and SARS infections, the WHO has recommended preventive measures to inhibit the transmission of acute respiratory infections. These interventions include (1) avoiding close contact with people suffering from common cold; (2) frequent cleaning of hands with running water or alcohol sanitizers; (3) avoiding excessive touching of eyes, nose, and mouth; and (4) avoiding unprotected contact with animals. In addition, people with acute respiratory infections should practice respiratory hygiene regularly, which includes maintaining a distance of $1 \mathrm{~m}$ from healthy people to avoid spread of airborne droplets, covering coughs and sneezes with clothing or disposable tissues, and frequent hand washing. ${ }^{1}$

Since the emergence of SARS-CoV-2, various international bodies have debated the use of N95 respirators and surgical masks. In their review on the use of masks and respirators for prevention of influenza transmission, Reza et $\mathrm{al}^{4}$ reported that effectiveness of masks is likely linked to their early, regular, and correct use; most studies have reported a reduced risk of upper respiratory infections with masks and respirators. Similarly, Jefferson et $\mathrm{al}^{5}$ reviewed the clinical effectiveness N95 respirators (95\%) and masks (68\%) in reducing the spread of respiratory viruses. In a debate organized by the Singapore Infection Control Association, Dr Lin proposed the adequacy of surgical masks for prevention of MERS-CoV transmission in addition to personal and environmental hygiene.

(C) 2020 by The Society for Healthcare Epidemiology of America. All rights reserved. This is an Open Access article, distributed under the terms of the Creative Commons Attribution licence (http://creativecommons.org/licenses/by/4.0/), which permits unrestricted re-use, distribution, and reproduction in any medium, provided the original work is properly cited. 